\title{
La Revista de Avance (1927-1930) Vocero de Vanguardismo y Pórtico de Revolución
}

T A revista de avance es un importante episodio en la historia literaria 1 de Cuba. Desde sus páginas el verso y la prosa reciben el impulso renovador de una época ansiosa de cambios profundos. No fue un órgano estridente del más violento vanguardismo, porque sus editores hicieron una selección cuidadosa y asimilaron solamente lo más productivo del arte nuevo. Ese equilibrio le permitió ser el medio por el cual Cuba se comunicaba con lo mejor del revolucionario mundo artístico que ya había surgido en Europa y América.

Mientras realizaba su misión literaria, la revista recoge también los empeños de un grupo generacional que nace en r923 para intentar la renovación integral de la vida cubana. Como en otros lugares donde llegó la insurrección artística, con ambiente propicio, encontramos en ella las primeras voces que anuncian una revolución general en el país. La suma de su fundamento ideológico, de las actitudes que allí se adoptan y de su material literario, confiere a la revista de avance la categoría de precioso instrumento de investigación. Es que "las revistas, cuando llegan a encajar en determinado momento histórico del arte $o$ de las ideas, vienen a șer un reflejo del período cultural en que les tocó vivir y sirven para iluminarlo o aun para revivirlo". 1 Y al "revivit" aquellos años vehementes, surgen ante nuestros ojos los orígenes de acontecimientos subsiguientes que merecen estudio. Sería aventurado afirmar que todo lo que nace alli (en el terreno de la cultura y la política), pasa hoy en Cuba, pero quizás no lo sería tanto concluir que todo lo que sucede

1 Félix Lizaso, "La revista de avance", Boletin de la Academia Cubana de la lengua, Vol, 10, Nos. 3-4 (julio-diciembre 1961), p. 19. 
en Cuba hoy tuvo allí su raíz, en aquella década entre r923 y I933, enmarcada por el nacimiento de un grupo generacional y una revolución: política. El centro cronológico de ese período histótico lo ocupa la revista de avance que se publica desde 1927 hasta 1930.

Reconociendo la trascendencia de aquellos años, se ha dicho en Cuba. recientemente: "los estudiantes de las letras cubanas tienen que revisar esta etapa ... porque es uno de los instantes más fecundos y más interesantes de nuestra vida intelectual".2 El "esfuerzo último" de las voluntades que entonces se conjugaton lo constituye la publicación de la: revista. Ella no recoge todos los matices de tan rico momento histórico -indiscutiblemente el más abundante y pródigo desde el nacimiento de: la República- pero sí sintetiza su ideario esencial y el énfasis renovador de la época. Llegó a ser como una resultante de las fuerzas que quisieron: conmover el acontecimiento artístico para trascender en la vida nacional. Por ese doble aspecto suyo se ha podido afirmar con justicia: "fue una revista intelectual, sí, una revista predominantemente literaria. Pero igualmente una revista con los ojos bien puestos en Cuba y en sus problemas. y con el ansia de verlos resueltos". ${ }^{3}$

Un estudio de esta singular publicación, por lo tanto, no puede limitarse a sólo un aspecto de la misma. Al ser vocero de un núcleo generacional con pretensiones tan amplias de renovación espiritual y artística, estamos obligados a medirla en esas dos dimensiones que la proyectan. con más acusado relieve. Su base ideológica podemos encontratla al analizar la revaloración del pensamiento martiano que allí se intenta. Iniciado en aquella década el "rescate de Marti", se enriquecen sus páginas con la valiosísima doctrina que luego sigue, polémica, proyectándose hasta. nuestros días. La estética de la revista se nos revelará al recorrer la ruta. impaciente del vanguardismo: sus luchas contra el medio hostil, su alcance poético y la razón última de su insurgencia.

Siguiendo una breve descripción de su más importante contenido, el estudio de esos dos aspectos - fundamental y formal- nos puede dar la mejor visión de la revista de avance.

\section{DEsCRIPCIÓN}

Durante sus cuatro años de vida la revista de avance publicó cin-

2 José Antonio Portuondo, "Mella y los intelectuales", Hoy, La Habana, 5 de enero de 1964.

3 Rosario Rexach, "La Revista de Avance publicada en La Habana, 19271930", Caribbean Studies, Vol. 3, $\mathrm{N}^{\circ} 3$ (octubre 1963), p. 6. 
cuenta números. El primero aparece fechado el I $_{5}$ de marzo de $1927 \mathrm{y}$ el último el I $_{5}$ de septiembre de I930. El ansia de renovación de sus. editores sugirió un título cambiante para la publicación; es así como la revista va apareciendo con el número del año: 1927, 1928, 1929 y 1930, pero el subtítulo revista de avance es el que ha prevalecido para identificarla.4 Además de los ordinatios, se publicaton algunos números especiales: el 25 está dedicado a Ramón Gómez de la Serna; el 28 a México y sus escritores; el 3 I a José Martí; el 42 es un homenaje a Waldo Frank con motivo de su visita a La Habana; el número 47 rinde tributo póstumo a la memoria de José Carlos Mariátegui. Los editores (que firmaron sus colaboraciones conjuntas como "Los Cinco" o simplemente "Los 5") fueron en su inicio Jorge Mañach, Juan Marinello, Francisco Ichaso, Alejo Carpentier y Martí Casanovas. Muy pronto entraron José Z. Tallet y Félix Lizaso a substituir a los últimos mencionados.

La más importante sección de la revista es la que denominaron "Directrices". Va apareciendo en cada ejemplar para decir el criterio editorial sobre temas y acontecimientos culturales, artísticos o políticos de Cuba y otros países. El primer comentario que allí escriben, expone los propósitos de la publicación: "Lo inmediato en nuestra conciencia, es un apetito de claridad, de novedad, de movimiento. ... Modestos coma somos, llevamos, eso sí, nuestra pequeña antena, lista para cuantos mensajes de otras tierras y de otros mares podamos interceptar en nuestra ruta. Los descifraremos, y hasta puede que seamos alguna vez osados en contestarlos".5 Años más tarde, las "Directrices" del último número presagian la tormenta donde cesará la revista. ${ }^{6}$ Sus editores se preguntan:

4 Aparece dividida en cuatro años. El año I (1927) lo forman dos tomos: el tomo I ( $326 \mathrm{pp}$.) contiene hasta el número 12 (30 de septiembre de 1927); el tomo II (140 pp.) hasta el número 17 (15 de diciembre de 1927). El año II (1928) - donde deja de publicarse cada quincena para convertirse definitivamente en mensual- corresponde con el tomo III (368 pp.) y contiene desde el número 18 al 29 (15 de diciembre de 1928). El año III (1929) corresponde con el tomo IV (380 pp.) y llega hasta el número 41 (15 de diciembre de 1929). El año IV (1930) corresponde con el tomo V (287 pp.) de sólo nueve números que completan los cincuenta publicados.

is "Al levar el ancla", revista de avance, Vol. I, No 1, p. 1. Después de cada cita daremos entre paréntesis el tomo, el número y la página de la revista. Evitaremos así el exceso de llamadas sin perjudicar el aspecto informativo de este trabajo.

6 Salió a la calle aquel último número con el suficiente retraso para incluir una protesta contra el gobierno por haber disuelto una manifestación estudiantil el 30 de septiembre. "Como consecuencia de esta dragonada [dice una nota de última hora], un estudiante acaba de morir al escribirse estas líneas". Era Rafael Trejo. Aquella muerte fue inicio de un nuevo período de la historia cubana. "Se rumora [concluía la nota] que por los sucesos ocurridos se suspenderán las garantías constitucionales, instaurándose la censura previa a la prensa, 
“A dónde vamos, a dónde queremos ir con esta política cuya crueldad sólo resulta levemente atenuada junto a su torpeza?" (V,50,258). Entre esos dos momentos extremos escribieron en aquella sección sobre el Centenario de Góngora $(I, 4,69)$, y el de Goya (III,2I,I5); auspician la exposición "Arte Nuevo" de pintura $(I, 3,4 \mathrm{I})$; protestan por el encarcelamiento de Mariátegui (I,8,I8I); defienden la Reforma Universitaria (I,9,2I3); denuncian la "norteamericanización de la prensa en la América Latina" (IV,35,I59); estudian el fundamento pesimista del carácter cubano y el "imperialismo económico" de los Estados Unidos (IV;4I, 35I); respaldan las "juventudes vanguardistas" (V, 46,I29); hacen un balance crítico de los veinticinco años de República $(I, 5,97)$; etc. En las secciones "Letras hispánicas" y "Letras extranjeras" se recogen abundantes notas sobre temas correspondientes, escritos por los directores de la revista y por valiosos colaboradores." En "Almanaque" se publicaban reseñas sobre la vida cultural europea y americana junto a las que reflejaban el acontecimiento nacional. De esa manera muchos empeños generosos recibieron el aplauso o la orientación de la mejor crítica cubana. ${ }^{8}$

en cuyo caso ' 1930 ', para no someterse a esa medida, suspenderá su publicación hasta que el pensamiento pueda emitirse libremente" (V,50,259). Tíes años más tarde y por algún tiempo, pudo "emitirse libremente el pensamiento"; pero ya había pasado la época de la metáfora y de la insurgencia artística. La revista de avance había cumplido su misión: nacida en la efervescencia del tricentenatio de Góngora, venía a morir con el asesinato en la plaza pública de un "leader" estudiantil.

7 Como ejemplos citaremos las que comentan: el estudio de Dámaso Alonso sobre las Soledades de Góngora $(1,6,146)$; Old Spain de Azorín $(\mathbf{I}, 1,13)$; Tirano Banderas de Valle Inclán $(I, 3,51)$; La agonía antillana de Araquistain (III,23, 159); Goya de Ramón Gómez de la Serna (III,25,210); Romancero gitano de García Lorca (III,27,289); Examen de conciencia de Guillermo de Torre (IV, 33,121); Seis ensayos en busca de nuestra expresión de Pedro Henríquez Uteña (III,27,291); El modernismo y los poetas madernistas de Rufino Blanco Fombona (IV,33,122); Antología de la poesía mexicana moderna de Jorge Cuesta (III,28, 329); Los de abajo de Mariano Azuela (II,14,52); Cuaderno San Martin de Jorge Luis Borges (V,43,60); Doña Bárbara de Rómulo Gallegos (IV,37,245); Don Segundo Sombra de Ricardo Güiraldes (IV,30,13); El roto de Joaquín Edwards Bello. Y sobre obras de autores cubanos: La poesía moderna en Cuba de Félix Lizaso y J. A. Fernández de Castro (I,5 113); Trópico de Eugenio Florit (V,50,283); Poemas en menguante de Mariano Brull (IV,30,25); El documento y la reconstrucción de José Matía Chacón y Calvo (IV,39,310); Juan Criollo de Carlos Loveira (III,22,130); Surco de Manuel Navarro Luna (IV,30,26); La nueva poesía en Cuba de Regino Boti (II,14,53). En "Letras Extranjeras" se comentaton obras de Philippe Soupault, Waldo Frank, Curcio Malaparte, Erich Maria Remarque, Henri Barbusse, Georges Duhamel, Sinclair Lewis, etc.

8 Quedaron allí anotadas y comentadas las conferencias de Maeztu, Manuel Herrera Laso, Américo Castro, Waldo Frank, García Lorca, Gregorio Marañón, Max Hentiquez Ureña, Porfítio Barba Jacob, José Vasconcelos, etc. También exposiciones, conciertos, inauguraciones, homenajes, y otras actividades del mundo cultural cubano. 
En un "Index Barbarorum" iba apareciendo la conciencia nacional del estilo. Desde aquella sección se enjuiciaba los errores y los abusos del lenguaje que cometían escritores o conferencistas descuidados. La constante vigilancia, al mismo tiempo que provocaba vivas discusiones, creaba un gusto más exigente entre los lectores cubanos. Además de las secciones fijas mencionadas, el cuerpo de la revista lo componen ensayos, composiciones poéticas, fragmentos de novelas, narraciones, semblanzas, críticas sobre literatura, pintura, música, teatro, etc.

Con la revista de avance aparecen, muchas veces por vez primera en español, obras de escritores europeos y americanos: en traducción de Mañach "La sabiduría de Avicena" de Jorge Santayana; del mismo autor, pero traducida por Pedro Henríquez Ureña, una selección de "Aversión al Platonismo". También publican cinco ensayos de Bertrand Russell con el título "La filosofía en el siglo xx"; cuentos de Blaise Cendrars, Paul Morand y Jules Supervielle; comentarios y crítica literaria de John Dos Passos, Ezra Pound, Henri Rambaud y Paul Valéry; un drama de Eugene O'Neill; recuerdos de Pierre Louis; "El negro y el Jazz" de Jeanneret; "Psicología y poesía" de Karl Jung. Y páginas de André Gide, Jean Giraudoux, Máximo Gorki, Sherwood Anderson y Máximo Bontempeli.

Valiosos escritores españoles e hispanoamericanos colaboraron en la revista. Entre ellos mencionaremos a: José Ortega y Gasset, Miguel de Unamuno, Alfonso Reyes, Américo Castro, Mariano Azuela, Celestino Gorostiza, Francisco Ayala, José Carlos Mariátegui, Guillermo Díaz Plaja, Horacio Quiroga, Benjamín Jarnés, Eugenio D’Ors, Carlos Alberto Erro, Luis Araquistain, Fernando de los Ríos, Luis Alberto Sánchez, Franz Tamayo y Miguel A. Arconada. Entre los poetas a: Federico García Lorca, César Vallejo, Juana de Ibarbourou, Salvador Novo, Jorge Cuesta, Xavier Villaurrutia, José A. Balseiro, Carlos Pellicer, Alfonso Camín, Bernardo Ortiz de Montellano, Luis Cardoza y Aragón, Manuel Maples Arce y Jaime Torres Bodet.

Muchas de las mejores páginas de Mañach, Marinello, Ichaso y Lizaso se escriben para la revista de avance. De ellos, y sólo como ejemplo, citaremos los siguientes ensayos: del primero, "Vanguardismo" $(I, I, 2)$, "Hay algo nuevo bajo el sol" (III,20,43), "Indagación del choteo" (III, 27,276), "El pensador en Marti" (IV,3I,40), "Vórtice del gusto nuevo" (IV, 34,I30); de Marinello: "El Insoluble Problema del Intelectual" (I,7,I68), "El momento" (I,I0,247), "Arte y política" (III,I8, 5), "El poeta José Marti" (IV,3r,44), "Sobre la inquietud cubana" 
(IV,4I,354). De Ichaso: "Crítica y contracrítica" (I,I,I3), "Góngora y la nueva poesía" (I,6,I27), "La crisis del respeto" (I,II,275), "Higiene del lenguaje" (II, I7,II7), "Ibsen y el muñequismo" (III,2I,77). De Lizaso: "Fernando de los Ríos, evocador" (III,r9,37), "La lección de Güiraldes" (III,22,II8), "Martí, o la vida del espíritu" (IV,3I,38), "Programa de criolledad" (IV,4I,358), "Bajo el signo de Martî" (V, 46,I44). Otros escritores cubanos que enriquecen la revista con sus colaboraciones son: Entique José Varona, Medardo Vitier, José María Chacón y Calvo, Alfonso Hernández-Catá, Ramiro Guerra, José A. Ramos, Luis A. Baralt, Roberto Agramonte, Lino Novás Calvo, Fernando Ortiz, Regino Boti, Carlos Loveira, Luis Rodríguez Embil, Raúl Maestri, Héctor Poveda, Raúl Roa y Carlos Montenegro. Y entre los poetas: Agustín Acosta, Eugenio Florit, Mariano Brull, José Z. Tallet, Emilio Ballagas, Alejo Carpentier, Ramón Guirao, Regino Pedroso, Manuel Navarro Luna y Andrés Núñez Olano.

Además de aquellas situaciones vinculadas al aspecto ideológico y estético de la revista - a los que nos hemos de referir con detalle más adelante-creemos conveniente destacar como momentos interesantes de su trayectoria:

x) Las discusiones sobre la "esencial incomprensión entre España y América", donde exponen sus puntos de vista Manuel Aznar, Ramiro de Maeztu, Franz Tamayo y Jorge Mañach $(I, 3,46)$.

2) La polémica entre Leopoldo Lugones y Luis Araquistain en la que éste último defiende la "dictadura inteligente" de Rusia frente a la "histriónica" de Italia y la "inepta" de España (I,2,22).

3) El respaldo a las declaraciones del grupo "minorista" -al que pertenecían los editores de la revista- en las que se pronunciaban a favor de: "la revisión de los valores falsos y gastados"; "la independencia económica de Cuba"; "el arte vernáculo y, en general, por el arte nuevo"; "la cordialidad y la unión latino-americana"; y contra: "los desafueros: de la pseudo-democracia"; y "el imperialismo yanki" $(\mathrm{I}, 5,97)$.

4) La reacción de la intelectualidad hispanoamericana para protestar, ante el gobierno de Cuba, por el encarcelamiento de dos editores de la revista. Se les acusaba de estar relacionados "con una presunta conspiración comunista" (I,10,245).

5) La respuesta a la "actitud paternal, indulgente y protectora" que asumieron algunos escritores españoles con ocasión del "Meridiano intelectual" (I,II,273).

6) La discrepancia con la revista Amauta de Mariátegui por haberse: 
publicado en la revista de avance una Oda "decadente" de Giménez Caballero (III,I9,46). Los editores cubanos defendieron la libertad de su posición vanguardista para justificar al poeta español (III,24,I7I). Y la defensa contra las imputaciones del pintor Diego Rivera, que acusó a la revista Contemporáneos de México y a la revista de avance de "aristocraticismo y alejamiento excesivo de las corrientes vitales" (III,28,332).

7) La indagación sobre lo que debe ser el arte americano (III,26, 235), y las respuestas -entre otras interesantes- de: Enrique José Varona (III,27,285), Alfonso Hernández-Catá (IV,30,24), Rufino Blanco Fombona (III,29,36I), José A. Ramos (IV,34,150), Víctor Andrés Belaúnde (IV,36,2I3), Eduardo Avilés Ramírez (IV,3I,55), Raúl Roa (IV, 37,242) y Jaime Torres Bodet (III, 28,313). El balance de esa encuesta lo realizó Ichaso para buscar una "veta común americana". Dice encontrarla en la norma que señaló Martí: "injértese en nuestras repúblicas ell mundo, pero el tronco ha de ser de nuestras repúblicas" (IV,38,258).

8) Las ediciones de la revista de avance que publicaron, entre otras, Tiempo muerto de Mañach, Juventud y vejez de Marinello, La poesít moderna en Cuba de Lizaso y Fernández de Castro, Góngora y la nueva poesía de Ichaso. Y también obras de Chacón y Calvo, Raúl Maestri, Florit, Boti, Luis Cardoza y Aragón, Sergio Carbó, etc.

Desde que en 1927 'se celebró la exposición de "Arte Nuevo", organizada por los editores de la revista de avance - siempre preocupados por las artes plásticas-en Cuba se considera oficialmente iniciado el vanguardismo. Aquel evento quiso ser "un esfuerzo consciente y desinteresado de renovación y de heroísmo" $(I, 5,99)$. Nunca se detuvo el interés de la revista por la pintura. Junto a reproducciones de obras de Jean Cocteau, Salvador Dalí, Maillol, García Maroto, Matisse, José Clemente Orozco, Pablo Picasso y Diego Rivera, aparecen las de los cubanos Abela, Angelo, Gattorno, Domingo Ravenet, Rafael Blanco, Carlos Enríquez, Víctor Manuel, Massaguer, Marcelo Pogolotti y Jaime Valls.

La revista de avance no olvidó mantener informados a sus lectores de las actividades musicales. Bela Bartok (IV,34,I30), Schoenberg (III, 2I,85) y el "sonido $\mathrm{I} 3$ " de Julián Carrillo $(I, 4,77)$, van apareciendo junto a estudios sobre la música cubana y sus compositores: Amadeo Roldán (III,26,244), Alejandro García Caturla (III,29,364) y el maestro Pedro Sanjuán (I,8.185). La Física, las Ciencias Sociales, la Economía Política, la Historia, la Arquitectura, la Cinematografia y los Deportes también se asomart allí con artículos sustanciales, para completar, en vivo reflejo, el interés omnimodo de la época innovadora. 


\section{Fundamento: Trincheras de ideas}

Para entender una generación, concebida como una "comunidad de espíritu, de sensibilidad, de actitudes, de preocupaciones y de rasgos estéticos generales"," deben analizarse las respuestas que ella ensaya para comprometer la historia, para torcer el acontecimiento qie se encuentra al nacer, conformando el futuro según su particular visión de la vida. En último término, una generación activa tiende a darle su contenido al suceso; no se conforma con que las cosas le pasen a ella, quiere ella pasarle a las cosas. Para lograrlo, de una serie de posibles soluciones escoge las que le parecen más efectivas para sus fines.

Los cubanos que empiezan a actuar como nueva generación desde I923 buscan en su pasado una doctrina coincidente con sus intimas ambiciones, que les sirva también de orientación a sus empeños. Sólo entonces, Cuba descubre verdaderamente a Martí. La ideología martiana respondía a las metas que se señalaba la época. Quizás aquel pensamiento extensísimo tenía mayor alcance y distinta amplitud que las posibilidades del momento en que se inicia su culto, pero su palabra se convirtió en impulso para lograr los objetivos generacionales. Martí llega a ser así el "héroe adorado" de toda una generación. ${ }^{10}$ Más adelante hemos de ver que las distintas actitudes - siempre con la misma "filigrana"- encuentran en Martí la base principal de su pensar y de su quehacer. ${ }^{11}$ Desde 1923 todos aquellos agonistas tomaron la decisión de rebelarse contra lo anterior. Sienten la caducidad del mundo artístico, social y político, y proponen las soluciones que les parecen mejores para vencer el pasado. Deciden entonces entronizar lo nuevo con todo el aparato que ello requiere. $Y$ ¿no fue Martí el gran innovador? Con una interpretación particularísima y fraccionada en tonos diversos - muchos de ellos antagónicos- el coro generacional, del que forma parte la revista de avance, ensayó sobre todos el himno martiano. El ritual de aquella religión nueva descubre una época.

9 Francisco Ayala, Tratado de Sociologia, II: Sistema de Sociologia (Buenos Aires: Editorial Losada, 1947), p. 157.

10 Usamos la categoría de "héroe adorado" con todo el sentido que le confiere el historiador alemán Julius Petersen en su estudio Las generaciones literarias en Filosofía de la ciencia literaria (México: Fondo de Cultura Económica, 1946).

11 José Ortega y Gasset explicó que en una generación, la variedad de actitudes entre sus miembros es de escasa importancia, pues lo trascendente no es aquello que los diferencia entre sí, sino lo que a todos distingue de la generación anterior. "Hay una común filigrana" - señala en El tema de nuestro tiempo-para los pro y los anti, los cuales "por mucho que se diferencien, se parecen más todavia". 5a. ed. (Buenos Aires: Espasa-Calpe Argentina, 1945), p. 15. 
En cuanto observamos ese culto concentrarse entre 1927 y 1930 , se hace evidente que buscan las raíces de la nacionalidad y la identidad de lo cubano para fundamentar su especial concepción del futuro. Esa era la orientación perdurable que ofrecia a los jóvenes escritores Fernando de los Ríos desde sus "Reflexiones en torno al sentido de la vida en Martí". En esa memorable conferencia les dijo: "los grandes hombres son la clave con que descifrar el enigma histórico de los pueblos, ya que ellos son exponentes máximos de sus virtudes larvadas, latentes o potenciales; en ellos podemos medir la altura del nivel espiritual alcanzado por las más exquisitas fuerzas de un pueblo". ${ }^{12}$ Cuba no había nunca intentado seriamente ese camino. Con muy valiosas excepciones, la primera época republicana no logró una decidida inspiración en Martí. Ni siquiera como escritor se le supo valorar. Pero desde 1926 ya señalaban Félix Lizaso y José Antonio Fernández de Castro, en su conocida antología poética, la influencia martiana llegando a los poetas que allí se llamaron "los nuevos": "El culto de Martí, que ya en esta hora no es un vano alarde de falsos discípulos, sino un complejo y amoroso conocimiento de su obra, parece dotar a los poetas de este grupo de una cualidad general y dominante: la sinceridad". ${ }^{3}$ Un cuarto de siglo después, el mismo Lizaso evoca el desarrollo en Cuba de aquel culto. Destaca entonces el significativo interés que logra la figura de Martí cuando se manifiesta el cambio generacional, es decir, "cuando se produce en Cuba ese cambio radical que tuvo por origen algunos hechos insignificantes al parecer, pero que trajeron una postura nueva ante la vida nacional, dando origen a una actitud crítica, como fueron la 'protesta de los trece', el 'grupo minorista' y el 'movimiento vanguardista'. Martí toma significación excepcional cuando la juventud se moviliza en sentido crítico y combativo frente a la vida nacional". ${ }^{14}$ Esa concurrencia de la "nueva actitud" y la nueva doctrina se produjo en las páginas de la revista de

12 Mensajes de la Institución Hispanocubana de Cultura, Vol. I (Julio 1928), p. 91. La significación que tuvieron para los cubanos aquellas orientaciones de Fernando de los Ríos fue recogida en un artículo de Félix Lizaso escrito para la revista de avance: "Todos conacíamos a Martí, y sin embargo, en aquella cálida evocación surgió la amplitud de un alma, la amplitud de un gesto, distendiéndose por todos los contornos, invadiendo la altura y la lejanía; vimos un Martí aún más grande, más alto, envolviendo en sus reflejos los ánimos vacilantes.

¿Sería excesivo decir que conocemos ahora mejor a Martí, a través de don Fernando de los Ríos, que vino a proyectar su luz, luz de iluminado, en la figura de nuestro grande hombre?" (III,19,37).

13 La poesía moderna en Cuba 1882-1925 (Madrid: Editorial Hernando, S. A., 1926), p. 326.

i4 José Martí, recuento de centenario (La Habana: Ucar García, S. A., 1953), Vol. I, p. 314 . 
avance. Quizás la indolencia fatalista y el pesimismo de los primeros cubanos independientes nazcan del desconocimiento, y algunas veces del mal conocimiento de Martí. Había caracterizado los primeros años de República la interpretación de externidad mayor, precipitada y falsa de una figura histórica que no podía revelarse en aquel medio. Pero los que siguieron después y se sintieron "pinos nuevos", no querían heredar aquel error. Cada generación tiene el derecho de inventar sus propias equivocaciones.

Con otros empeños del cambio de actitud en Cuba, la incorporación de Martí al ritmo de la vida afectiva es reclamada por los intelectuales. "A los héroes de espada y caballo, el pueblo los glorifica sin trámites [dijo Jorge Mañach] a los otros, hay que enseñarles a glorificarlos". ${ }^{15}$ $\mathrm{Y}$ desde las páginas de la revista de avance sus editores explicaron la misión que sentían imperativa de su quehacer: el "rescate de Martí": conferirle la "estatura cabal" que merecía "su héroe adorado". Escriben entonces desde "Directrices":

Martí sigue siendo entre nosotros un ilustre desconocido. A nuestra generación parece tocarle el duro privilegio de comenzar a comprenderle en su grandeza histórica y humana. No es que neguemos la labor meritísima de recopiladores y comentaristas de su obra ni que desconozcamos el serio valor de algún que otro ensayo sobre su acción política y su producción vastísima. Negamos, sí, que hasta ahora se haya hecho la labor que dé a propios y extraños la estatura cabal de nuestro héroe, el cuidadoso comprensivo análisis de su vida y de su "papeleria", la síntesis de magno alcance que nos pondere la significación plena de aquella existencia iluminada. $(\mathrm{IV}, 3 \mathrm{~T}, 36)$.

Para lograr ese objetivo, se imponen una tarea que va formando la estructura ideal de la revista: Abogan por la edición definitiva de las obras completas de Martí (III,24,I7I), luchan para atraer los niños cubanos al estudio del Maestro (IV,35,x59). Se defiende al héroe (IV, 37,223) y se aplaude su culto $(V, 43,35)$. Lizaso señala la "exuberancia ideológica" en la selva martiana (IV,3I,38), mientras recomienda "hacer ejercicios espirituales con sus virtudes" $(\mathrm{V}, 46, \mathrm{r} 44)$. Mañach sigue las ricas vertientes de su doctrina (IV,3I,40). Ichaso alaba las "calicatas" que les revelarán toda su oculta riqueza $(\mathrm{V}, 44,90)$. Marinello descubre

15 Pasado vigente (La Habana: Editorial Trópico, 1939), p. 185. 
el mensaje de Martí para la nueva rebeldía estudiantil $(I, 3,45)$ y la inspiración de su palabra poética $(I V, 3 I, 44)$. Medardo Vitier estudia las influencias que convergen en su obra (IV,38,268); Hernández-Catá entrega a la revista el primer capitulo de su Mitologíal de Marti (II,I4, 40); Roa persigue la novedad artística de los Versos sencillos (I,I0,254); y se publican pensamientos inéditos del Apóstol (IV,3 I,37).

No murió con la revista de avance aquella devoción: en sus páginas quedaban hechos los votos de Mañach y Marinello.16 Pero la disensión de sus interpretaciones sobre el pensamiento de Martí, marca la importante división que surge en el pensamiento cubano. "Puede decirse que así como entre ellos se bifurcó el camino que conducía la meta deseada - la superación de nuestra vida nacional, en último término- de igual modo se separó el camino que seguiría nuestra juventud". ${ }^{17}$ La revista de avance quedó en el umbral de aquellos derroteros. Marinello aceptó el credo comunista que hizo su entrada en Cuba el mismo año que nace la generación de 1923. Desde entonces, con muchos de sus seguidores, no ha desistido la búsqueda de apoyo a su dogma en el universo martiano. "Mella arranca de Martí y en su previsión pone la planta incansable", ${ }^{18}$ dijo del fundador del partido; y en el prólogo de las Obras completas de Martí, que en nueva edición se iniciaton el pasado año en Cuba, llega a afirmar: "La patria martiana, construida por la revolución encabezada por Fidel Castro, es la que lleva a todos los cubanos la obra del libertador". ${ }^{19}$ Pero Jorge Mañach, después de toda una vida adentrada en el pensamiento del Apóstol, apartándolo de interpretaciones que le parecen sacrílegas, muere en el destierro - al igual que Francisco Ichaso-como un símbolo del otro camino martiense.

Desde los días de la revista, Félix Lizaso dedicó su vida al estudio del Místico del deber. ${ }^{20}$ También alejado de Cuba escribe sobre su tema precioso.21 Sin duda será el último de aquel grupo de "Los Cinco" que

I6 La coincidencia de sus iniciales (J.,M.) con las de José Martí hacía suponer a los lectores de la revista que estaban predestinados a una misión martiana.

17 Félix Lizaso, Panorama de la Cultura cubana (México: Fondo de Cultura Económica, 1949), p. 142.

18 Prólogo de Juan Marinello a Glosando los pensamientos de José Martí de Julio A. Mella (La Habana: Editorial Berea, 1941), p. 8.

19 José Martí, Obras Completas (La Habana: Editorial Nacional de Cuba, 1963), Vol. I, p. 19.

20 De él dijo Francisco Romero: "su encuentro con la sambra de Martí es como el hallazgo de su propio destino". "Homenaje a Félix Lizaso", Revista de la Habana, Vol. IX, No. 52 (1946), p. 60.

21 Su última publicación "Normas periodísticas de José Martí", Revista Iberoamericana, Vol. XXIX, No. 56 (Julio-Diciembre 1963). 
defenderá a Martí de la dialéctica marxista; ha escrito en su más reciente ensayo:

¡Y si viera Martí su patria convertida en el mayor feudo del materialismo, en lo más ajeno al espiritualismo que jamás se haya dado en nuestra América, cómo iba a sufrir su espíritu delicado y tierno que una vez habló de que nuestros campesinos lo que necesitaban era una campaña de ternura! ¿Y cómo podría soportar ver su tierra, aquella tierra por la que luchó toda su vida para ver en ella la libertad y todos los bienes que ella apareja, aquella tierra que besó al desembarcar con Máximo Gómez y la "mano de valientes", ultrajada por gente extraña a su fe, a su amor, a su espiritualidad?22

La ruta ideológica de Martí, cuyas inmensas posibilidades se demuestran con las interpretaciones divergentes, fue seguida por la revista de avance. En la medida que la época y las capacidades biográficas de sus editores lo permitieron, allí les llegó la prevención antimperialista de quien le había conocido "las entrañas al monstruo", para denunciar continuamente el "paulatino desangramiento de las patrias del Caribe, bajo las ventosas del tentáculo yanki" (III,23,I59), y para censurar la peligrosa aquiescencia de algunos gobierno de América con "el vecino formidable". También quisieron para su país una república "independiente de extraños y propios", y combaten el caudillismo que se apoderaba de Cuba, pronunciándose "contra las dictaduras políticas unipersonales" $(I, 5,97)$. El amor a la libertad de quien afirmara que un pueblo se hacía "con los derechos y opiniones de sus hijos todos", les obligó a proclamar que "no puede tenerse por punible el hecho de profesar determinadas tendencias políticas o sociales" $(I, 9,23)$. Martí dijo: "iA caballo, la América entera!" para que la palabra honrada de Enrique José Varona contestara en eco desde la revista: "¡En pie, pueblos del Caribe!" (V, $47, I 61)$. Y como "no hay odio de razas, porque no hay razas", se protestaba de las injusticias contra los negros $(\mathrm{V}, 45,97)$; y porque él recomendó que "la universidad europea ha de ceder a la universidad americana", alli se dijo que "ningún creador de América nos debiera ser más extraño que cualquier medianía europea" (IV,40,3I9); y como hay que "conocer el país, y gobernarlo conforme al conocimiento", en consecuencia advitieron: "Fijémonos primero en lo nuestro" $(\mathrm{V}, 47, \mathrm{I} 60)$. El pretender p. 31

22 "Nuestro Marti", Política (Venezuela), Vol. III No. 34 (Mayo 1964), 
la hermandad espiritual con las repúblicas americanas, el culto a la nacionalidad, el mejoramiento social y cultural de Cuba, y la fe en un destino superior por la evolución política del pueblo, también les llegaba con el idealismo de la generosa doctrina.

Pero en aquella revista literaria, con su vasta actividad intelectual, mientras se forja vacilante el ideario de una mejor ciudadanía, parece, sobre toda otra palabra, inscrito el apotegma martiano: "Trincheras de ideas valen más que trincheras de piedras". ${ }^{23}$

Forma: La primera prosa

Aunque la revista de avance no tuvo al vanguardismo como censor excluyente de otras manifestaciones artísticas, es indudable que aquella tendencia de renovación completa fue su más usada y rica vestidura, $y^{\prime}$ los logros que con él nacieron forman la mejor aportación en el terreno literario. Con toda la fuerza de su ambigüedad, el vanguardismo concentra el ansia de general insurgencia en el elemento formal de la revista. ${ }^{24}$ Era más fácil romper las reglas del arte académico que el ritmo social y político: el universo equilibrado del conformismo en las letras era vulnerable al disparate vanguardista como no lo podían ser, a otras armas ruidosas $\mathrm{e}$ indiscretas, la tradición y la costumbre.

Al iniciarse la publicación de la revista de avance se hacía necesario definir sus lineamientos estéticos. Mañach aprovecha los tres primeros números para dejar sentadas las bases de la nueva doctrina con sus ensayos "Vanguardismo", "La fisonomía de las épocas" y "El imperativo temporal". Integradas y más o menos perfiladas las fuerzas europeas de innovación artística, le sirven para postular sus principios: "Aquel gesto desabrido hacia lo aquiescente, lo estático, lo prestigioso del tiempo, aquella furia de novedad que encarnaron Marinetti, Picasso, Max Jacob, han formado escuela" $(I, I, 2)$. Resume entonces la fórmula de aquel arte nuevo con la búsqueda de una "mayor cantidad de actualidad real en la menor cantidad de lenguaje", y prescinde - como siempre hicieron los movimientos de vanguardia- de la irracionalidad contenida en los ele-

23 José Martí, Obras completas (La Habana: Editorial Lex, 1953), Vol. II, p. 105.

24 Su dualidad misteriosa sólo se explica por la beligerancia de sus fines. "Expresa la revolución y la reacción, anticipa el futuro y prolonga el pasado, se conduce como compromiso y evasión; es trascendente y trivial, profundo y frívolo, minucioso y negligente, aplicado y displicente. Pero es posible quebrar ese hechizo de indefinición, decidiendo su sentido revolucionario". Marcos Maidanik, Vanguardismo y Revolución (Montevideo: Editorial Alfa, 1960), p. 136. 
mentos de aquella ecuación. El alejarse de la lógica es precisamente lo que puede comunicar el sentido de los nuevos tiempos; sin los elementos deformadores que maneja el artista, sería imposible trasmitir el mensaje que nace con una distinta sensibilidad: "Una pierna monstruosa de Picasso o de Epstein logra su finalidad actualizante y emocional tan bien o mejor que una pierna fidelísima de academia. Aquélla, aparte superior elocuencia plástica, nos dice más claramente, aunque con mảs arbitraria referencia a lo externo, el sentido de la época desmesurada que vivimos" $(\mathrm{I}, 3,44)$. Además de explicar y justificar las más comunes manifestaciones de los movimientos vanguardistas de la posguerra (afán destructivo, negación del pasado, embriaguez nihilista, afirmación del presente e interés por todo lo nuevo, la deshumanización, desrealización e intrascendencia del arte) con los que aparece emparentada la revista de avance (futurismo, ultraísmo, dadaísmo, etc.), alli se hace, por adelantado, un balance de los beneficios que debe lograr la revolución artística: "No sólo ha de devolvernos la vieja vida; sino también prepararnos para la nueva: hacernos llevadera, es decir, inteligible, la vida de nuestro tiempo" $(\mathrm{I}, 3,43)$.

Pronto desde aquella revista se descubre otra inspiración que la ya señalada llegándole de su "héroe adorado". Los versos de Martí contienen elementos preciosos para la nueva poesía y se establece un segundo vínculo con el Maestro. "Antes que los ultraístas, ya él había proclamado -en alguno de sus prólogos relampagueantes-, la sencillez de la forma", dice Roa desde su "Martí, poeta nuevo" y añade esta observación de gran interés para los vanguardistas: "Había cantado en páginas de acero la belleza trepidante de los puentes". Al coincidir el culto por el mártir de la independencia con la fiebre de renovación artística, es fácil explicar que se le quisiera también como precursor estilístico de la época. ${ }^{25}$ Por eso se llega a afirmar allí: "En alto grado poseyó Martí -innatamente-el sentido de la poesía vanguardista... Esencialmente nuevos son los Versos sencillos. Cualquier poeta de vanguardia puede firmarlos como propios sin traicionar sus ideales estéticos, por muy avanzados que éstos sean" $(1,10,254)$.

La más curiosa interpretación del vanguardismo cubano desde el extranjero, la ofreció Miguel de Unamuno. En carta que envió a los edi-

25 No le faltaba cierta razón al vanguardismo cubano. "En lo estrictamente poético [ha señalado Alfredo A. Roggiano], sorprende encontrar formas inclusive posmodernistas y hasta creacionistas: comercio ducle, verde envidia, aire bueco, movible viento, rio de luz sobre los bombres, celeste avcricia, son ejemplos en donde las sinestesias conforman la metáfora y la imagen plástica se convierte en vida interior de la palabra". "Poética y estilo de José Marti", Antología crítica de José Martí (México: Editorial Cvltvra, T. G., S. A., 1960), p. 68. 
tores de la revista decía: "En mi bien poblada soledad del destierro fronterizo me entretengo y solazo con su $1928 \ldots$. Hoy, leyendo el último número, me ha salido lo que sobre el vanguardismo les doy a la vuelta y que entrará en mi próximo libro, un cancionero de doble frontera". $Y$ sus versos eran una colección de riquisimos simbolos que encerraban el secreto del nuevo arte:

$\mathrm{Y}$ bien, esas aguas rotas cahorzos en medio del desierto buscan... ¿qué buscan?

No buscan, esperan la gran avenida que las unza y nazca del poniente el río; río que arrastre en légamo los árboles con su hojarasca seca, ruinas de chozas y hasta de palacios, cunas y tumbas, tronos y tajos, estrados, escaños y ruedos, cetros, báculos, metros y cayadas, ruecas y espadas y bastos

y oros y copas, pitos y flautas, camas y mesas, tinas $\mathrm{y}$ artesas, hasta que al fin se encauce en las riberas por donde ayer no más se iba a la mar el río eterno. (III,27,269)

Cuando ya se encauzaba "en las riberas" el movimiento vanguardista, es decir, cuando aquel fraccionamiento ingenuo de la realidad tomó parte activa en la vida y en el pensamiento de Cuba ("por donde ayer no más se iba a la mar el río eterno"), Marinello señalaba la misión que estaba cumpliendo la rebeldía del arte. Consistía en penetrar las esferas culturales y propagar el espíritu de insurgencia, advirtiendo cómo "Ias fuerzas retardatarias" que dominaban el panorama intelectual cubano, desconfiaban de los violentos gestos vanguardistas y del radicalismo de sus teorías. "Suponen no con mucho error [decía de los gobernantes de la época], que las nuevas formas y los impensados contenidos son resonancia de insatisfacciones vitales $\mathrm{y}$ aspectos marginales - $\mathrm{y}$ anticipados- de un 
nuevo estado". Luego explicaba el por qué ni las instituciones oficiales ("en su plácido usufructo del pasado"), ni el gran público ("analfabetos que saben leer") podían asimilar fácilmente la estética del tiempo. Pero la sugestión de la nueva teoría ganaba terreno en su proselitismo apostólico. "Sería injusto no reconocer [concluía diciendo el ensayista] cómo el contrabando burla las barreras de la incomprensión y del personal interés, cómo las nuevas inquietudes van ganando - en lo plástico y en lo literario- soldados y batallas. Nuestra realidad política da cabida a la desesperación. Nuestra realidad intelectual, artística, da lugar a la esperanza" $(\mathrm{V}, 43,52)$. Es que la movilidad inquietante del vanguardismo conquistaba nuevos horizontes de progreso que no se vislumbraban para los otros problemas de Cuba. Había nacido ya en la poesía "social" la denuncia contra la antigua escala de valores y la idealización del trabajo, para ver surgir con la poesía "negra" lo autóctono y la tragedia del hombre de color. Junto a ella, la poesía "pura" lograba con su desdén por lo inmediato otra forma de particular rebeldía. En esas: dimensiones se resuelve la historia poética del vanguardismo cubano durante los años de la revista de avance. ${ }^{26}$

La primera en aparecer es la tendencia negra. Se manifiesta discretamente en unos versos de Alfonso Camín con "inconfundible sabor criollo":

\author{
¡Damasajova, Damasajova! \\ Pelo brillante de ala de chova. \\ Diana de bronce. Verso africano. \\ Noche y luceros. Carey cubano...
}

Luego se desarrollará hasta "Liturgia" de Alejo Carpentier, que se publica en el último número de la revista:

\title{
La Potencia rompió ¡yamba ó!
}

26 Eugenio Florit aclaró el error de llamar poesía de vanguardia a la que nace después de la revista. Dijo en una conferencia pronunciada el año pasado: "De él nace [del vanguardismo], o mejor dicho, él se resuelve en esas dos tendencias principales ya mencionadas [poesía pura y poesía negra]. Lo que ocurre es que se ha solido dar la calificación de 'vanguardista' a toda la poesía nueva escrita después de la revista de avance y ello ha producido grandes confusiones y errores de apreciación". "Mariano Brull y la poesía cubana de vanguardia", XI Congreso del Instituto Internacional de Literatura Iberoamericana, Universidad de Texas, Austin, 29 de agosto de 1963. 
Retumban las tumbas

en casa de Acué.

$(\mathrm{V}, 50,260)$

La tonalidad del vanguardismo aparece con los últimos destellos de "los nuevos" en la poesía de Juan Marinello:

Como que esta mañana

-oro gozoso sobre las viejas azoteas--

es más alegre en nuestros pechos jóvenes

(parece que tu mano hace un rato ha nacido)

echemos alegría en la mañana.

Y en "Ferroviaria" de José Z. Tallet:

Marchamos por la vida como las paralelas

del tren. Y los dos somos de hierro tal cual ellas.

Como la suya es nuestra superficie pulida

y brillante. (Las ruedas repasan por encima).

Al lado de la explosión vanguardista no podía faltar el canto obligado a la revolución soviética. La gesta del pueblo ruso provoca el elogio idealizado de la poesía nueva: la violencia, la rebelión contra el pasado, la anarquía, la novedad y la libertad aparente, encuentran parentesco espiritual con sus doctrinas artísticas:

Sobre el Volga

se ha helado el lamento

Sueltan los bateleros

Una jauría de carcajadas rojas

las maromas son corbatas de la muerte.

La Historia arroja dioses
como cáscaras secas
vuela polvo de símbolos rotos
entre negras pavesas de Zares.

$(\mathrm{I}, 3,54)$

La presencia de la poesía pura se manifiesta en la obra de Mariano Brull. El silencio evasivo de la realidad cotidiana funciona como desprecio y como denuncia: 
La catedral engarzada en el ojo

-cubista-

del vitral azul y rojo

gira, - anillo de Saturno-

al sol que muere en un guiño.

El fondo: campo de armiño.

$Y$ pronto aparece la desarticulación del vocablo y las maromas tipográficas del más ardiente momento vanguardista en "Azotea" de Navarro Luna:

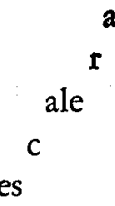

a

un sudor de bullicio

1

me corre por el cuerpo

s

$y$

para tomarme un vaso de silencio

en la azotea

Pero el vaso se me

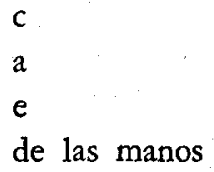

rascándole el vientre a la noche

con sus uñas

y a los gatos

res-ca-bu-che-án-do-le los senos a la luna. $\quad(\mathrm{r}, 7, \mathrm{r} 66)$ 
Con su poema "Proletario", Lino Novás Calvo inaugura en Cuba la poesía de denuncia contra la explotación del trabajador. Aquella protesta constituye uno de los mejores ejemplos de esa derivación poética del vanguardismo:

\author{
Hombre: \\ me interesa tu vida, \\ toda tu absurda y macerada vida, \\ que arrastras, sin sentirlo, \\ por esos bajos fondos. \\ Tostado por el sol \\ y el dolor de la fragua, \\ se ha cumplido el deseo señorial \\ del anquilosamiento de tu espíritu.
}

No sólo se iniciaron importantes modalidades de la poesía cubana en la revista de avance. También escritores y poetas comienzan allí sus carreras literarias. Entre ellos mencionaremos a Eugenio Florit, ${ }^{27}$ que en una docena de composiciones dejó lo mejor de la poesía nueva:

Los vientos oceánicos

ahogaron

un grito de estupor

Pájaros extraños

rasgábanlos con sus plumas metálicas.

Ensordecíanlos

con sus ruidos

-Aquellos pájaros no píaban; mordían

los vientos con rugir inusitado-.

Y los vientos misoneístas

batieron alas de revolución.

27 "Procede, como todo artista consciente de nuestra época, de las huestes del llamado vanguardismo, que fue para él, como para otros muchos, purifica. ción y aprendizaje, gimnasia y disciplina. Se da a conocer en la revista de avance, de la que salieron Mañach, Marinello, Tallet, Ichaso, Lizaso, todos los escritores que se han destacado en la literatura cubana de los últimos quince años". Angel del Río, Eugenio Florit, vida y obra (New York: Hispanic Institute, 1943), p. 12. 
y acribillaron con sus dardos

a los pájaros de metal.

Hemos señalado la entrada y proyección del movimiento vanguardista dentro de su vocero cubano. Allí se ejercitó el pensamiento que adquiere con él nueva dimensión y atrevida elasticidad. Allí aprendió a burlar la tiranía de la regla artística el lector y el poeta. Con el vanguardismo se estrenó la insolencia necesaria para realizar una revolución, pues era evidente que el pasado se mostraba vulnerable. A la sombra del arte nuevo se movían interpretaciones diversas sobre el alcance último de la renovación, pero todos unían sus ataques contra lo "viejo" con un mismo espíritu de rebeldía. Martí Casanovas, que perteneció algún tiem. po al grupo de editores de la revista, dejó en sus páginas opiniones cuya violencia es frecuente en todos los "ismos" de la época: "El arte nuevo, por ley natural, obligada, es un arte revolucionario, destructivo, que acaba a fuerza de golpes y arremetidas briosas con todo lo viejo, con los prejuicios tradicionales, con la rémora farragosa del ochocientos; no es, em. pero, ni puede serlo aún, un arte constructivo, afirmativo, eficaz" $(I, 7,157)$. Que el vanguardismo aspiró en Cuba a una renovación básica del medio y del sistema de vida que lo vio nacer, hay abundante testimonio de sus propulsores. Del alcance que se propuso escribió Francisco Ichaso en un artículo titulado "Sobre un rótulo vacilante": "El movimiento moderno, dentro de su apariencia deportiva, dentro de su deseada ingenuidad, dentro de su sencillez juguetona, implica una trascendente transformación del espíritu, que en modo alguno puede traducirse con la cáscara caediza de un formalismo más o menos curioso" (II, I3,6).

A la terminación del proceso revolucionario, que se había iniciado en I930 cuando moría la revista de avance, Jorge Mañach medita sobre el papel que jugó la rebelión en el arte. Descubre la misión de aquella insurgencia escondida bajo el manto estético como preludio de la revolución:

El estilo de escribir, de pintar, de pensar, se iba haciendo cada vez más ágil $y$ flexible, más apto para ceñirse a las formas esquivas de la idea o de la emoción. Más capaz de brincar grandes trechos de lógica sin perder la gravedad. Más dispuesto para transfigurar imaginativamente las cosas. Esto ya en sí estimulaba el ansia de una realidad nueva... El vanguardismo fue, en la vertiente cultural, el primer síntoma de la revolución. No digo, claro está, 
que fuesen los vanguardistas quienes hicieron lo que hasta ahora se ha hecho: digo que ellos contribuyeron mucho a sembrar el ambiente de audacias, de faltas necesarias de respeto, de inquina contra los viejos formalismos estériles. ${ }^{28}$

Se mostraba así, desde dentro, el significado de la insurgencia vanguardista. Detrás de cada una de sus respuestas violentas se escondía un objetivo intocado en lo circundante. Aquella beligerancia inacabable era una sublimación artística de la insatisfacción ciudadana. Así considerado, el elemento formal de la revista merece especial atención. Las excentricidades vanguardistas que allí se manifestaron, dejan de ser meros caprichos que deben descansar en el fondo de las antologias; son como jeroglíficos modernos que esconden la esencia misma de una época. Desde su Historia y Estilo Mañach explicó las asociaciones posibles entre los verdaderos fines del ataque y el símbolo que lo encubría. Y fue revelando el alma misma de la estética nueva para concretar su vaguedad y despejar su misterio:

Aquella rebelión contra la retórica, contra la oratoria, contra la vulgaridad, contra la cursilería, contra las mayúsculas y a veces contra la sintaxis, era el primer ademán de una sensibilidad nueva que ya se movilizaba para todas las insurgencias. Lo que negábamos en el arte, en la poesía y en el pensamiento era lo que había servido para expresar un mundo vacío ya de sustancias, vacío de dignidad y de nobleza. Nos emperrábamos contra las mayúsculas porque no nos era posible suprimir a los caudillos, que eran las mayúsculas de la política. ... Deformábamos las imágenes en los dibujos, porque lo contrario de esa deformación eta el arte académico, y las academias eran baluartes de lo oficial, del favoritismo y la rutina y la mediocridad de lo oficial. Alentábamos lo afro-criollo, porque veíamos en ello una insurgencia sorda, un intento por romper la costra de nuestra sociedad petrificada. ${ }^{29}$

Interpretado de esa manera, aludiendo a un mundo que se intenta destruir y del que no se habla directamente, golpeando la realidad con sus imágenes vertiginosas, el vanguardismo de la revista de avance se nos aparece, él mismo, como una gigantesca metáfora que muere en la des-

28 "El estilo de la revolución", Historia y Estilo (La Habana: Editorial Minerva, 1944), p. 98.

29 Ibid., pp. 96 y 97. 
nudez de una revolución triunfante, cuando el impulso íntimo de su rebeldía trasciende del secreto - como el tropo poético cuando rompe todo su misterio. Detrás de él y de la revista quedaban vencidos "el conformismo en la política, el modernismo en la poesía, el naturalismo en la novela, el discursismo en la prosa y el lugar común y la improvisación en todas partes". ${ }^{30}$

Toda la generación que volcó sus mejores escritores en aquella publicación de vanguardia, habló con el lenguaje nuevo que se atrevió a ser, alguna vez, protagonista del drama. Porque "nadie se libra de su tiempo, que por mil modos sutiles influye en la mente, y dicta, sentado donde no se le puede ver ni resistir, los primeros sentimientos, la primera prosa". ${ }^{31}$

Queens College

Carlos Rupoli

30 Lizaso, Panotama..., p. 132.

31 Martí, Obras completas (La Habana: Editorial Lex, 1953), Vol I, p. 766. 